\title{
Assessing Undergraduate Business Degree Outcomes: A Comparison Of Two Universities
}

Robert W. Caldwell Jr., (Email: Caldwell@universe.uiwtx.edu), University of the Incarnate Word Jan R. Moore, (Email: jmoore@sosu.edu), Southeastern Oklahoma State University Michael Schulte, (Email: mschulte@concentric.net), University of the Incarnate Word

\begin{abstract}
The importance of outcomes assessment has produced innovative course developments and resulted in enhanced Capstone educational experiences for undergraduate students at both universities. This collaborative paper compares the evolution and outcomes assessment of the Capstone business course as a fundamental component of the business curriculum, discusses initiatives to provide even greater educational opportunities for students, assessing effectively over the continuum, and keeping the courses current to the university and business environments.
\end{abstract}

\subsection{Background}

outheastern Oklahoma State University in Durant, Oklahoma (SOSU) and the University of the Incarnate Word (UIW) in San Antonio, Texas both offer business programs at the baccalaureate and graduate level and are accredited by the Association of Collegiate Business Schools and Programs (ACBSP). SOSU is accredited by the Commission on Institutions of Higher Education of the North Central Association of Colleges and Schools and UIW is accredited by the Southern Association of Colleges and Schools.

The University of the Incarnate Word (UIW) is located in San Antonio, Texas and has an enrollment of approximately 4300 students. Degrees are granted at three levels - Bachelors, Masters, and Doctorates. Educational programs include Nursing, Education, Business Administration, Science and Engineering and traditional Liberal Arts. A Virtual University (on-line) and an Adult Completion Program (AdCap), as well as various off campus arrangements, also provide a broad range of educational opportunities. In business, the areas of specialization (majors) are Accounting, Finance, Marketing, Management and International Business. The curriculum is traditional with a required business core of 42 hours and 18 hours required for the selected area of specialization. A university core requirement of 68 hours and electives complete the 128 hours to be completed for graduation.

Southeastern Oklahoma State University (SOSU), a regional university in Durant, Oklahoma, is located 90 miles north of Dallas, Texas, and 15 miles north of the Red River dividing Oklahoma and Texas. The student body is comprised of about 4,000 students primarily drawn from rural communities and small towns in Southeastern Oklahoma and North Central Texas. Initially a teacher's college beginning in June 1909, SOSU still continues to graduate teachers but has expanded its mission to include baccalaureate and masters level degree programs in Business Administration as well as Education and a number of Liberal Arts disciplines. Classes are offered in the traditional classroom, via the Interactive Educational Television (IETV) media, as well as on-line. SOSU broadcasts to five remote education centers/campuses located at Ada, Ardmore, Idabel, Midwest City, and McAlester, Oklahoma through the IETV system. The Masters of Business Administration (MBA) courses are offered exclusively via this medium. Continuing Education classes are also offered to the same area communities. There are 727 declared majors in Business Administration degree programs at the Bachelors level (BBA) and 52 MBA

Readers with comments or questions are encouraged to contact the authors via email. 
students. Majors include Accounting, Business Information Management, Business Education, Training and Development, Finance, Management and Marketing (Self Study Report for ACBSP, Summer 2002).

The School of Business also offers Bachelor of Science degrees in Aviation, Aviation Management, Business Education and Leadership. All but Business Education and Leadership are offered as major-minors (no additional minor required). Leadership is offered as a 30 hour major but only with a second major (double major). Additionally, minors in Business (24 hours) and in Leadership (18 hours) are offered. The School of Business is seeking a third accreditation as it enters pre-candidacy in 2003 for accreditation by the Association to Advance Collegiate Schools of Business (AACSB).

The curriculum for SOSU's BBA degree is comprised of a 36 hour Business Core and 24 hours in the area of specialization (major) for Business Information Management and Business Training and Development majors which have 33 core hours and 30 hours in their respective majors (Undergraduate Bulletin 2000-2002, Volume 83, July 2000).

\subsection{Curriculum Development And Initiatives}

Both universities have continued to enhance and innovate in their goal to educate and produce graduates with the necessary skills and knowledge to be successful in the business world

At UIW, the Capstone concept began at the MBA program level in 1983 with a course entitled Cases in Management Problems. Outcomes centered on discipline-specific education, analytical skills, application capability, professional writing and oral presentation skills and meeting accreditation agencies' requirements. The concept evolved as an outcomes assessment instrument for the MBA, MBA International Business, and Master of Arts in Administration programs.

For undergraduates, a Strategy and Policy course was made a core requirement for all business majors in 1988 partially because of the success of outcomes assessment and student acceptance at the graduate level. Initially, one Capstone course was required; however, beginning with Spring 2002 semester, two courses, Capstone I and Capstone II, BMGT 4380 and BMGT 4381, will be required of all business students (see below for Capstone Requirements at both Universities). This initiative, Enhanced Outcomes Assessment through Capstone Course Innovations, was presented in an earlier March 2002 Applied Business Research Conference.

The Capstone course requirement at SOSU is satisfied with the undergraduate level Business Policy course (MNGT 4633) and at the graduate level by Strategic Management course (MNGT 5603). The undergraduate Capstone course taken in the student's final semester is intended to teach the students to integrate functional-area knowledge and skills to be applied at the corporate level and the business level in a strategic decision making context. This intent is the same as for the Capstone courses at UIW.

Students are expected:

- $\quad$ To illustrate the need to focus previously acquired management/business skills in a manner that allows effective long range planning.

- To develop in the student an understanding of, and a capability to perform, a SWOT analysis.

- $\quad$ To give the student an appreciation for the relationship between the organization's physical structure and its ability to set objectives, plan actions and implement them, to evaluate progress and control the organization.

- To assist the student in understanding the need to match the organization's capabilities with the opportunities in its environment and to help them develop the skills that will allow them to do so. 
- $\quad$ To impart an understanding of the organization in a structural sense and to point out how structure, in conjunction with leadership and a system of rewards, provides the means by which the organization achieves its objectives (Business Policy MNGT4633 Syllabus, Fall 2002).

\subsection{Outcomes Requirements}

The outcomes that are expected from undergraduate business administration programs are derived from several different, but equally valid sources. The accrediting agencies have specific criteria regarding expected outcomes that govern what their member universities must achieve in order to be accredited. The Common Profession Components (CPSs) specified by ACBSP of course content leading to the BBA degree are:

- $\quad$ Business Functions and Operations (Production and Operations Management, Marketing, and Business Finance).

- $\quad$ Economic/Social/Legal Environment (Legal Environment of Business, Economics, and Business Ethics).

- Quantitative Methods and Information Systems (Accounting, Management Information Systems, and Quantitative Techniques/Statistics).

- Organization Theory and Interpersonal Behavior (Management, Organization Behavior, and Human Resource Management).

- $\quad$ Administrative Processes and Policy (Business Policies and a Comprehensive Integrating Experience). This experience enables a student to demonstrate the capacity to synthesize and apply knowledge (e.g.: course, thesis, comprehensive examination from an organizational perspective).

- Global Dimension of Business. Students seeking the BBA degree expect to be prepared, through their studies and the university experience, to be able to perform the tasks in the workplace. A second expectation is that they will be prepared to enter graduate programs to expand their competencies in their chosen field (Association of Collegiate Business Schools and Programs, 2003).

UIW and SOSU develop goals for their respective programs that reflect the specific focus the administration and the faculty believe will meet the expectations of the student, accrediting agency, and prospective employers.

UIW has established the following goals for its BBA programs:

- $\quad$ Goal 1: Mission. A student with an undergraduate degree in business from the University of the Incarnate Word will be able to demonstrate an awareness of domestic and global social issues, and the role of business in solving them.

- Goal 2: Competency. A student with an undergraduate degree in business from the University of the Incarnate Word will be able to demonstrate the fundamental practices of business.

- Goal 3: Critical Thinking and Writing. A student with an undergraduate degree in business from the University of the Incarnate Word will be able to demonstrate the ability to think critically and communicate complex ideas through writing.

- $\quad$ Goal 4: Technology Proficiency. A student with an undergraduate degree in business from the University of the Incarnate Word will be able to demonstrate technological proficiency in the use of an industry standard spreadsheet application. 
The mission of the School of Business at SOSU and its manner of implementation is "...to prepare students to complete and perform successfully in diverse careers in business and related fields by providing a quality academic experience. Undergraduate and graduate programs and their respective curricula will remain responsive to social, economic, and technological developments. The mission is implemented through the design of learning opportunities that:

- $\quad$ Provide an awareness and understanding of the economic, political, and social environments in which business operates.

- Develop interpersonal skills, communication skills, and analytical business skills.

- $\quad$ Build self-confidence and the capacity to make effective and efficient use of skills, learning situations, and experiences in a changing business environment.

- Utilize critical thinking for recognition of potential business problems and creative problem solving.

- Instill a sense of intellectual curiosity that fosters lifelong learning and pursuit of knowledge.

- $\quad$ Serve as a resource for business and to provide public service to the community through cooperative programs, economic development programs, internships, consultative programs, and scholarly activities.

In fulfilling this mission, the School of Business strives to attract, motivate, educate and develop students of high caliber. The degree programs offered reflect the needs of constituents as well as the standards of accrediting agencies and professional associations to which it holds itself accountable" (Undergraduate Bulletin 2000-2002, Volume 83, July 2000, p. 179).

\subsection{Outcomes Assessment}

The methods used to assess the outcomes of a BBA program vary between these two universities. In this part of the paper, we will explore the use of Capstone experiences at each school to determine the level of competence achieved by their students.

At UIW, the Capstone course Business Policy and Strategy (BMGT 4375) was designed to enable students to demonstrate their competencies - applying the education they have received in the discipline specific courses, to solve real-world problems facing businesses (2001-2003 Undergraduate Bulletin, Volume 7, Number 1, July 2001). .

The course requires students to perform rigorous and substantive analysis of all business functions and to prepare and present comprehensive written and oral reports of their findings and recommendations. These reports formed the most objective and concrete evidence to assess the outcomes of the BBA programs and were used to document these outcomes during the accreditation process. As previously stated, the Capstone experience has been expanded into two core courses entitled Integrative Business Analysis and Decision Making, I \& II (BMGT 4380 / 4381). This requirement is being implemented in Spring 2003 following successful prototype testing in the Summer and Fall 2002. The content of the courses consists of developing a process for strategic business analysis, in-depth research and analysis of business function, and industry differences, extensive written and oral reporting, and analyses of businesses / organizations in the community. The respective course structures follow:

BMGT 4380: The first 8 weeks are devoted to familiarization with process as is currently done with the second half of the course involving detailed analysis and application of the process to the various functional areas of businesses: operations, marketing, finance, international, etc. Written reports of analyses and oral presentations will be required throughout the entire course.

BMGT 4381: The first 8 weeks devoted to application of the process (developed in BMGT 4380) to various industries, primarily by those that represent employment opportunities for the students with second half of 
the course will be devoted to the students working with project client companies to gain "real world" exposure and test their competency with direct feedback from outside the classroom in addition to that provided by the instructor. Guest speakers representing functional areas as well as diverse industries will be invited to bring insights from outside academia to the students. Additionally, field trips to appropriate venues will also be available to further broaden the students' exposure to the business environment.

The Outcomes Assessment effort at SOSU is comprised of four levels:

- Entry level assessment and planning is required for new students who lack proficiency in the "basics" of reading, writing and math. These students must successfully complete courses designed to help them develop those skills. Additionally at-risk freshmen as well as undecided freshmen are required to complete an orientation course to motivate them toward educational goal clarification, classification of self-concept and the clarification of values. They also are to improve their study, test-taking skills and management of time.

- $\quad$ Mid-Level Assessment is conducted at the junior level to evaluate their proficiency in general education subjects including, again, reading writing and math as well as science reasoning and critical thinking. This is accomplished through the administration of one or more standardized examinations. Portfolios of certain work/activities are maintained by the students in an effort to provide feedback for the process.

- $\quad$ Program Outcomes Assessment is conducted by way of exit examinations to determine the level of program goal achievement. Nationally standardized examinations are used in all programs where such exams are available and locally developed tests are used when necessary. Seniors are also assessed through capstone courses, seminars, internships, recitals and field experiences. Again, the results are used as feedback to improve the various curricula.

- $\quad$ Student Satisfaction is measured annually through students and alumni surveys. These surveys include institutional services as well as programs.

The self-study of the Management and Marketing Department of the School of Business at SOSU found the following developments: There has been a decrease in enrollment in the management major during the period fall 1996 to spring 2001; the high of 165 in fall 1996 to the lows of 83 and 87 for fall 2000 and spring 2001. There has been an increase in marketing majors from 63 in fall 1996 to 74 in spring 2001 with a low of 49 in spring 97 and a high of 78 in spring 2000 .

\subsection{Lessons Learned}

The Capstone course package in place at UIW is providing students with a comprehensive and effective platform to demonstrate their competence in applying their business education. By requiring concentrated research and analysis of the functional areas of business activity, students are developing a keen understanding of the process of business decision making.

Slightly lower management enrollments and reduced numbers of students declaring management or marketing for their major at SOSU can be attributed to the student perception of these programs as increasingly more demanding. This increase in rigor results from: (1) the revision of curriculum to meet new accreditation standards (ACBSP), (2) the accompanying increased expectations of the faculty, and (3) the increased number of professors with doctoral degrees. This reduction in enrollment and in major declaration is not alarming when viewed in light of the increased ACT scores. As the programs have become more robust and the standards increased, fewer, but more highly capable students are being attracted. 


\subsection{Recommended Actions}

At UIW, efforts to apply to continued emphasis on curriculum development and faculty staffing are expected to broaden the base for providing top quality education to its students. And at SOSU, efforts will continue to raise standards and faculty expectations for student performance in the belief that the drop in enrollment is only temporary and we will return to or exceed previous levels but with students that are more motivated and determined to excel.

\subsection{Current Initiatives}

UIW is conducting an aggressive initiative that will establish a comprehensive system of continuous improvement in the content and quality of business education provided to students. Spearheaded by the Dean of the School of Business Applied Arts and Administration, visits to Capstone classes by the dean and selected functional discipline professors have resulted in everyone associated with preparing students for the Capstone experience gaining substantial insight into the students' capabilities. Expectations for this initiative are two fold: functional discipline professors will be able to interact with and evaluate the students' retention of theories and concepts being taught and secondly, students' competence in applying this material to the decision making process will be enhanced. The ongoing nature of this initiative, when institutionalized will provide a vehicle for continuously improving and assessing the BBA program at this university.

At SOSU, the Business Information Management curriculum is being reworked and will emerge anew in fall 2003 as a Management Information Systems degree program. Three endowed chairs have been or are being added in Finance, Accounting, Management Information Systems, and a fourth in a discipline, yet to be decided, will be filled in spring 2003. As a result of a recent (2003) increase in the rigor of the curriculum and an increase in academic standards, there has been a decrease in management and marketing major declarations over the same period.

During the Spring 2003 semester, as this is being written, the SOSU School of Business Student Affairs Committee is developing and is in the second draft stage of a document intended to track BBA and MBA graduates to obtain feedback for assessment and other purposes. Another first for SOSU is the requirement that students take the Graduate Management Acceptance Test (GMAT) before applying for graduate school. The GMAT requirement begins with the Fall 2003 semester. The initial required minimum score will start at a modest level and will be increased as deemed appropriate. Also, the ETS graduate level exit examination will be administered for the first time in the MBA Capstone course Strategic Management (MNGT 5603). This testing will occur during March 2003. Additionally we are currently (Spring 2003) initiating the use of a computerized business simulation in the MBA Capstone course, Strategic Management (MNGT 5603). The program is a multi-functional decision-making software package that will require teams to "operate a business". The intent is to make this program or a more sophisticated version of it, a permanent part of the Capstone syllabus and to use it as another assessment tool for our graduate program. Plans for Fall 2003 are to also adapt this approach to the undergraduate Capstone course, Business Policy (MNGT 4633) for the same purposes.

\subsection{Assessment Effectiveness}

All graduating seniors at SOSU's business department are required to take the Educational Testing Service (ETS) Major Field Achievement Test (MFAT) in Business during their last semester of study. This test is administered each fall and spring semester to majors graduating that semester or the following summer semester as a requirement of the Capstone course MNGT 4633. The student scores on the test are converted to a 100 point scale and are used in determining the final semester grade (Undergraduate Bulletin 2000-2002, Volume 83, July 2000). 
MANAGEMENT AND MARKETING MAJORS

Major Field Achievement Test Results (Educational Testing Service)

\begin{tabular}{|l|c|c|c|c|c|c|c|c|c|c|}
\hline Areas & F96 & S97 & F97 & S98 & F98 & S99 & F99 & S00 & F00 & S01 \\
\hline Accounting & 37.9 & 39.2 & 36.7 & 42.0 & 40.5 & - & 45.1 & 43.1 & 39.2 & 40.4 \\
\hline Economics & 32.6 & 37.5 & 34.3 & 35.6 & 35.7 & - & 36.3 & 38.5 & 34.5 & 35.8 \\
\hline Management & 52.4 & 56.1 & 52.0 & 48.4 & 52.6 & - & 53.5 & 56.7 & 51.4 & 52.6 \\
\hline Quant. Bus. An. & 49.8 & 57.9 & 51.7 & 45.0 & 43.2 & - & 45.9 & 50.0 & 44.8 & 46.4 \\
\hline Finance & 40.5 & 44.0 & 40.8 & 30.8 & 29.1 & - & 29.8 & 31.1 & 32.7 & 31.6 \\
\hline Marketing & 57.5 & 60.5 & 58.0 & 45.9 & 50.0 & - & 45.5 & 51.4 & 45.3 & 47.7 \\
\hline Legal/Social Environment & 55.2 & 56.0 & 54.8 & 36.0 & 35.6 & & 43.1 & 50.1 & 39.2 & 43.0 \\
\hline International. Issues & 41.5 & 50.3 & 48.7 & 39.2 & 44.0 & & 41.8 & 47.7 & 38.9 & 46.1 \\
\hline Base & $(21)$ & $(32)$ & $(23)$ & $(35)$ & $(14)$ & & $(16)$ & $(34)$ & $(43)$ & $(43)$ \\
\hline
\end{tabular}

Source: Self-Study Report for ACBSP. (Summer, 2002).

Outcome effectiveness of the Capstone experience at UIW can be described as follows:

\section{Student Preparation For Employment}

Student evaluations at the conclusion of the Capstone consistently reflect that although the course is rigorous, they feel fully prepared to enter the work force.

Reports from business executives, based on observations of student teams performing client analysis, indicated that students' are well prepared and competent to function effectively in the "real world."

\section{Responses To Accreditation Requirements}

The content and results, in the form of course syllabi and student reports, both written and oral, show conclusively that common professional components are being covered. Additionally, students' ability to apply their education in a practical business setting is clearly demonstrated. Student competence in applying technology to research, analyze, and present their findings is evident.

With respect to the goals stated previously, we can state unequivocally, that the Capstone experience and the students' results provide conclusive proof that these goals are being met by the curriculum of the BBA programs.

An additional benefit of the Capstone experience has been the opportunity to involve the faculty responsible for delivering the discipline-specific education across the entire spectrum of the BBA program to review student reports and, in some instances, to participate in the classroom. This interaction enables connectivity between the educational foundation they provide and the outcomes assessment process as conducted in the Capstone. This win-win proposition provides for continuous improvement in the quality of the BBA education.

\subsection{Conclusions}

The continuous emphasis on team, group, and organizational interaction - student teams and other class groupings and their required interface with actual businesses require that we continue to improve our assessment process. If our students are to meet the needs of a constantly changing technologically driven business environment, we must take a dynamic approach both on the university through an internal pre-test/post-test approach and externally through student tracking efforts designed to gain feedback on our students' performances which becomes both the final test for our institution and the basis for curriculum and assessment method change.

In addressing and fulfilling the needs of their students, successful colleges and universities should take a more community and collaborative approach in truly preparing their students for the future - dynamic, changing, and increasingly global. This paper has taken such a collaborative approach in sharing and evaluating programs. $\mathbb{D}$ 


\section{References}

1. Association of Collegiate Business Schools and Programs. (2003). Available at http://www.acbsp.edu/

2. Business Policy MNGT4633 Syllabus. (Fall 2002). School of Business, Southeastern Oklahoma State University, Durant, Oklahoma.

3. Self-Study Report for ACBSP. (Summer, 2002). Management and Marketing Department, School of Business, Southeastern Oklahoma State University, Durant, Oklahoma.

4. Undergraduate Bulletin 2000-2002, Volume 83. (July 2000). Durant, OK: Southeastern Oklahoma State University. Available at www.sosu.edu/

5. Undergraduate Bulletin 2001-2003, Volume 7, Number 1. (July 2001). San Antonio, TX: University of the Incarnate Word. Available at www.uiw.edu/

Notes 